\title{
Effects of Orai3-Mediated Store-Operated Calcium Entry on Parathyroid Hormone Release in Secondary Hyperparathyroidism
}

\section{Zhangying Lin}

First Affiliated Hospital of Anhui Medical University

\section{Shuhao Wang}

First Affiliated Hospital of Anhui Medical University

\section{Yanxun Han}

First Affiliated Hospital of Anhui Medical University

Junwei Zhu

First Affiliated Hospital of Anhui Medical University

\section{Suwen Bai}

Anhui Medical University

\section{Hailong Shen}

First Affiliated Hospital of Anhui Medical University

\section{Yang Fang}

Anhui Medical University

\section{Peikun Li}

Second Affiliated Hospital of Anhui Medical University

\section{Bing Shen}

Anhui Medical University

Yehai Liu

First Affiliated Hospital of Anhui Medical University

KaileWu ( $\nabla$ wukaile@ahmu.edu.cn )

First Affiliated Hospital of Anhui Medical University https://orcid.org/0000-0002-6578-5000

\section{Research Article}

Keywords: Secondary hyperparathyroidism, Orai3, Calcium signal, Parathyroid hormone

Posted Date: February 18th, 2021

DOI: https://doi.org/10.21203/rs.3.rs-205615/v1 
License: (c) (i) This work is licensed under a Creative Commons Attribution 4.0 International License. Read Full License 


\section{Abstract}

Secondary hyperparathyroidism (SHPT) is a common complication of chronic kidney disease, is characterized by elevated parathyroid hormone (PTH) secretion and Hypocalcemia. Orai3 is a highly selective calcium (Ca2+) channel that plays important roles in tumor development, cardiovascular disease, and autoimmune diseases; however, its role in SHPT is unclear. In the present study, RNA sequencing and western blot assays were used to detect the expression levels of Orai3 in parathyroid tissue from patients with SHPT and from individuals without SHPT. Ca2+ imaging was used to detect the effect of Orai3 channels on Ca2+ signaling in parathyroid gland cells. Enzyme-linked immunosorbent assays were used to detect changes in PTH release. Orai3 knockout rats were used to detect the effect of decreased Orai3 expression on serum PTH levels. We found that the expression of Orai3 in parathyroid tissue obtained from patients with SHPT was significantly higher than that in patients without SHPT. Knockdown of Orai3 in parathyroid cells by transfection with Orai3-specific small inhibitor RNA inhibited store-operated Ca2+ entry (SOCE) in parathyroid cells. Inhibition of SOCE or knockdown of Orai3 significantly inhibited PTH release in parathyroid cells. PTH levels in the blood of Orai3 knockout rat were significantly reduced. Therefore, Orai3 expression and Orai3-mediated $\mathrm{Ca} 2+$ signaling may be a mechanism underlying PTH release, and Orai3 may play a role in the development of SHPT.

\section{Introduction}

Secondary hyperparathyroidism (SHPT), a common complication of chronic kidney disease (CKD), is characterized by elevated parathyroid hormone (PTH) secretion and parathyroid hyperplasia. Moderate (stage 3 and stage 4) chronic kidney disease affects more than $8 \%$ of Americans [1]. The prevalence of SHPT in CKD stage 3 is $71.3 \%$, and $79.7 \%$ in CKD stage 4, indicating that CKD is frequently complicated by SHPT, leading to increased risk of morbidity and mortality [2-4](!!! INVALID CITATION !!! ; Komaba et al. 2010). Hypocalcemia continuously stimulates PTH secretion and leads to hyperplasia of the parathyroid gland [5] as well as to unbalanced bone remodeling, soft tissue and vascular calcification, and increased risk of cardiovascular events and all-cause mortality [6]. Understanding the molecular and cellular mechanisms underlying SHPT should thus improve treatment strategies and patients' prognosis.

PTH levels are inversely correlated with intracellular calcium $\left(\mathrm{Ca}^{2+}\right)$ levels. Stimulation of certain cellsurface receptors induces $\mathrm{Ca}^{2+}$ release from the endoplasmic reticulum (ER). Decreases in $\mathrm{ER} \mathrm{Ca}^{2+}$ content trigger the accumulation of the $\mathrm{ER} \mathrm{Ca}^{2+}$ sensor protein stromal interaction molecule 1 (STIM1) into puncta located close to the plasma membrane. This accumulated STIM1 activates Orai family proteins, allowing $\mathrm{Ca}^{2+}$ entry to refill the ER [7]. Store-operated $\mathrm{Ca}^{2+}$ entry (SOCE), which occurs through STIM proteins located in the ER and Orai proteins located on the cell membrane, is an important mediator of extracellular $\mathrm{Ca}^{2+}$ entry into cells. Three subfamilies of Orai proteins (Orai1, Orai2, and Orai3) form the pores of highly $\mathrm{Ca}^{2+}$-selective store-operated channels (SOCs) [8,9]. Orai1, Orai2, and Orai3 have been identified as being structural elements in $\mathrm{Ca}^{2+}$ release-activated $\mathrm{Ca}^{2+}$ channels that refill the sarcoplasmic/ER Ca ${ }^{2+}$ stores after $\mathrm{ER} \mathrm{Ca}^{2+}$-store depletion [10]. Orai protein mediation of $\mathrm{Ca}^{2+}$ signaling 
is involved in a variety of physiological and cellular processes as well as in some pathological processes, including cardiovascular disorders, cancer, and neurodegenerative diseases [11]. Of the three identified Orai protein subtypes, Orai3 is receiving increased attention. Orai3-mediated SOCE has been shown to contribute to invasion and colony formation in an estrogen receptor-positive breast cancer cell line [1214]. Orai3-mediated SOCE has also been studied in adult normal and hypertrophied cardiomyocytes [15]. In addition, the decreased redox sensitivity of effector human T helper lymphocytes correlates with increased expression of Orai3 [16]. However, it is unknown whether Orai3 is involved in the regulation of $\mathrm{Ca}^{2+}$ signaling in parathyroid cells or in the release of PTH.

In the present study, we first evaluated RNA sequencing data to assess whether Orai3 expression levels differed in the parathyroid glands of patients with vs. without SHPT. We then explored the potential importance of Orai3 in $\mathrm{Ca}^{2+}$ signaling and in the release of PTH by using immunohistochemistry analyses, $\mathrm{Ca}^{2+}$ imaging experiments, small interfering RNA (siRNA) techniques, enzyme-linked immunosorbent assays (ELISAs), and Orai3 knockout rats.

\section{Materials And Methods}

\section{Participants and tissue specimen collection}

Parathyroid tissue specimens for the control group were obtained from patients with unilateral thyroid micropapillary carcinoma via a tracheoesophageal groove lymph node dissection. Parathyroid tissue specimens for the experimental group were obtained from patients with SHPT and renal failure via parathyroidectomy. All specimens were collected at the First Affiliated Hospital of Anhui Medical University. Patients or their families provided written informed consent prior to the specimen collection process. This study was approved by the Ethics Committee of Anhui Medical University (Anhui Medical Ethics approval No. 20190381). All experimental procedures conformed to the requirements of the Declaration of Helsinki and of clinical management.

\section{Tissue culture and transfection of human primary parathyroid cells}

The parathyroid tissue was repeatedly rinsed with sterile phosphate-buffered saline (PBS) prior to the removal of the fatty tissue envelope and connective tissue. The parathyroid tissue was cut into blocks of $2 \mathrm{~mm}^{3}$. The blocks were treated with collagenase $(2 \mathrm{~g} / \mathrm{L})$ in a $37^{\circ} \mathrm{C}$ water bath for $90 \mathrm{~min}$. The resulting suspension was filtered through sterile gauze and centrifuged at $1000 \times g$ for $5 \mathrm{~min}$ at room temperature. The collected cell pellets were resuspended in DMEM/F12 medium with $10 \%$ fetal bovine serum and placed in 6-well culture plates incubated at $37^{\circ} \mathrm{C}, 5 \% \mathrm{CO}_{2}$, and $95 \%$ relative humidity. The cells were transiently transfected with human Orai3-specific siRNA using Lipofectamine 3000 and Opti-MEM (Invitrogen; Carlsbad, CA, USA). The sequence (5'-GGGUCAAGUUUGUGCCCAUdTdT-3') was designed by and obtained from Biomics Biotechnologies.

\section{Western blot assay}


Western blot assays were used to evaluate the protein levels and the transfection efficiency of Orai3 siRNA. The protein extract prepared using RIPA Lysis Buffer (P0013B, Strong; Beyotime; Shanghai, China) was centrifuged at $4{ }^{\circ} \mathrm{C}$ and $12000 \times g$ for $20 \mathrm{~min}$. The supernatant was mixed with SDS-PAGE Sample Loading Buffer (P0015L; Beyotime; Shanghai, China) using a ratio of 4:1. The protein was separated by $10 \%$ sodium lauryl sulfate-polyacrylamide gel electrophoresis and then transferred to polyvinylidene fluoride membranes (Millipore; Burlington, MA, USA) and blocked with 5\% skim milk at room temperature for $1 \mathrm{~h}$. The membranes were incubated with antibodies against Orai3 (ProteinTech Group, Chicago, Illinois, USA) or $\beta$-tubulin or GAPDH (Biosharp; Hefei, China) overnight at $4{ }^{\circ} \mathrm{C}$. The membranes were washed with a PBS Tween 20 (PBST) solution (0.05\% Tween 20) and incubated with the secondary antibody. After being rinsed three times in PBST buffer, the membranes were visualized with an ECL light emitting system (Shanghai Peiqing Technology Co., Ltd; Shanghai, China). The optical density (OD) of each blot was analyzed using the software ImageJ (National Institutes of Health; Bethesda, MD, USA) and is presented herein as a relative OD value.

\section{Ratiometric calcium imaging}

The cytosolic $\mathrm{Ca}^{2+}$ concentration $\left(\left[\mathrm{Ca}^{2+}\right]_{\mathrm{i}}\right)$ was measured as in our previous report [17]. In brief, primary parathyroid cells were loaded with $10 \mu \mathrm{M}$ Fluo-8/AM in $\mathrm{Ca}^{2+}{ }^{2}$ free PBS, which contained $140 \mathrm{mM} \mathrm{NaCl}, 5$ $\mathrm{mM} \mathrm{KCl}, 1 \mathrm{mM} \mathrm{MgCl} 2,10 \mathrm{mM}$ glucose, $0.2 \mathrm{mM}$ EGTA, and $5 \mathrm{mM} \mathrm{HEPES}, \mathrm{pH} \mathrm{7.4,} \mathrm{at} 37^{\circ} \mathrm{C}$ for $20 \mathrm{~min}$. The cells were treated with ATP $(4 \mu \mathrm{M})$ for 10 min to consume intracellular $\mathrm{Ca}^{2+}$ stores. $\mathrm{Ca}^{2+}$ influx was initiated by applying $1 \mathrm{mM}$ extracellular $\mathrm{Ca}^{2+}$. The fluorescence was recorded using a Leica TCS SP5 confocal laser scanning microscope system. The change in $\left[\mathrm{Ca}^{2+}\right]_{i}$ is presented as a ratio of the fluorescence intensity following experimental treatment (F1) relative to the fluorescence intensity at baseline (F1/F0) for Fluo-8/AM.

\section{PTH assay}

The collected cell supernatant or serum was processed according to the instructions included with the ELISA kit (Elabscience Biotechnology Co., Ltd; Wuhan, China). In brief, each sample was placed in four or five wells, appropriately diluted, added to the enzyme plate, and blocked at $37^{\circ} \mathrm{C}$ for $90 \mathrm{~min}$. The reaction solution was discarded and the plate was rinsed five times with rinsing solution. The enzyme-labeled antibody was incubated with cells at $37^{\circ} \mathrm{C}$ for $60 \mathrm{~min}$. The substrate was added and the cells were incubated in the dark at room temperature for $15 \mathrm{~min}$. Once the color was satisfactorily developed, the solution to stop the reaction $(50 \mu \mathrm{L})$ was added, and the OD value was measured at a wavelength of 450 $\mathrm{nm}$ using a microplate reader. The OD value was positively correlated with the PTH concentration, and the PTH concentration in the sample was calculated using a standard curve. The changes in PTH release were evaluated under the different experimental treatment conditions. The data presented are from at least three independent experiments.

\section{Orai3 knockout rats}




\section{Statistical analysis}

GraphPad Prism software, version 5.0 (GraphPad Software; San Diego, California) was used to analyze the experimental results of Mann-Whitney tests (two-tailed). The experimental data are expressed as mean \pm standard error of the mean (SEM). Two-sided values of $P<0.05$ were considered statistically significant.

\section{Results}

\section{Expression level of Orai3 is increased in SHPT}

We identified Orai3 transcripts in parathyroid tissue from three control patients and from three patients with SHPT. The generated clustergram describes the genes differentially expressed between the two groups (Figure 1a), and the heatmap shows that Orai3 was significantly increased in SHPT compared with normal tissue (Figure 1b). We used western blot assays to detect expression levels of Orai3 in three pairs of parathyroid tissues from control individuals and patients with SHPT. The results showed that compared with normal tissue, the expression of Orai3 protein in SHPT was increased (Figure 1c, d). These results suggested that Orai3 was potentially one of the proteins in $\mathrm{Ca}^{2+}$ channels affecting $\left[\mathrm{Ca}^{2+}\right]_{i}$.

\section{SOCE is decreased in Orai3-deficient cells}

ATP acts on inositol 1,4,5-trisphosphate $\left(\mathrm{IP}_{3}\right)$ to activate $\mathrm{Ca}^{2+}$ release from the ER. By blocking sarco/endoplasmic reticulum $\mathrm{Ca}^{2+}{ }^{2+}$ ATPase (SERCA), thapsigargin (TG) passively depletes $\mathrm{Ca}^{2+}$ from the ER and prevents SERCA from filling the ER with $\mathrm{Ca}^{2+}$, thereby activating SOCE to allow extracellular $\mathrm{Ca}^{2+}$ influx. To explore the $\mathrm{Ca}^{2+}$ entry mechanism in parathyroid cells, we used TG or ATP to deplete $\mathrm{Ca}^{2+}$ from the ER and activate SOCE. BTP2 abolishes TG- or ATP-induced $\mathrm{Ca}^{2+}$ release and SOCE. Here, parathyroid gland cells were treated with ATP $(100 \mu \mathrm{M})$ or TG $(2 \mu \mathrm{M})$ in a $\mathrm{Ca}^{2+}$-free saline solution for $10 \mathrm{~min}$, after which $1 \mathrm{mM} \mathrm{Ca}^{2+}$ was added to the extracellular solution (Figure 2). $\mathrm{Ca}^{2+}$ release was activated by ATP or TG. The subsequent $\mathrm{Ca}^{2+}$ entry into parathyroid cells in the presence of extracellular $\mathrm{Ca}^{2+}$ was inhibited by the SOCE inhibitor BTP2. This result indicated that SOCE is a mechanism regulating $\mathrm{Ca}^{2+}$ entry into parathyroid cells.

Many studies have shown that STIM1 and Orai1 proteins are involved in SOCE. To assess whether Orai3 contributes to SOCE in parathyroid gland cells, we transfected primary cultured parathyroid gland cells with Orai3-specific siRNA to suppress Orai3 expression. Compared with cell transfected with scrambled RNA (control), ATP-induced $\mathrm{Ca}^{2+}$ release was not altered in cells transfected with siRNA; however, the subsequently activated SOCE was inhibited by approximately $50 \%$ after Orai3 knockdown (Figure 3 ). These findings suggest that Orai3 is a crucial component mediating SOCE in parathyroid cells.

\section{Effect of Orai3 on PTH release from human parathyroid cells}


The experimental results to this point indicated that the Orai3 channel mediated extracellular $\mathrm{Ca}^{2+}{ }_{\text {influx }}$ in human parathyroid cells and that the activation of these Orai3-mediate $\mathrm{Ca}^{2+}$ channels caused an increase in $\left[\mathrm{Ca}^{2+}\right]_{i}$. In order to further examine the effect of $\left[\mathrm{Ca}^{2+}\right]_{i}$ on PTH release in human parathyroid cells, primary cultured human parathyroid cells were seeded in 96-well plates at an appropriate density and subjected for $12 \mathrm{~h}$ to one of four treatments: application of DMSO (control) or of the SOCE inhibitor BTP2 $(10 \mu \mathrm{M})$ or transfection with scrambled siRNA or Orai3 siRNA. The cell medium was collected and analyzed using an ELISA kit to detect the level of the PTH release from the cells into the cell medium after the treatments (Figure 4a). The results indicated that treatment with the SOCE inhibitor BTP2 or transfection with Orai3 siRNA inhibited PTH release from human parathyroid cells, suggesting that Orai3mediated SOCE participated in PTH release.

\section{Blood PTH levels in Orai3 knockout rats}

The latter aforementioned experiments studied the effect of $\left[\mathrm{Ca}^{2+}\right]_{i}$ changes on PTH release from parathyroid gland cells at the cellular level. In this experiment, we assessed PTH release at the animal level by using an ELISA assay commonly used for clinical detection of PTH levels to assess PTH levels in blood derived from the tail vein of Orai3 knockout and control rats. (Figure 4b). We found that the PTH level in blood obtained from Orai3 knockout rats was significantly lower than that obtained from control rats. This result provided additional evidence for our findings at the level of the cell that Orai3 participates in PTH release.

\section{Discussion}

In the present study, we investigated the role of Orai3 in the parathyroid gland. Through RNA-sequencing (RNA-seq) analysis and western blot assays, we found that Orai3 was highly expressed in the parathyroid glands of patients with SHPT. In parathyroid cells, SOCE was activated by ATP or TG but was inhibited by BTP2. SOCE was also inhibited after Orai3 knockdown, resulting in decreased PTH secretion. Therefore, we propose for the first time, to our knowledge, that Orai3 regulates extracellular $\mathrm{Ca}^{2+}$ influx in parathyroid gland cells and mediates PTH secretion.

SHPT is characterized by parathyroid hyperplasia, with abnormal increases in the synthesis and secretion of PTH. SHPT pathogenesis includes decreased calcitriol production due to elevated serum levels of fibroblast growth factor 23 (FGF23) to maintain phosphate homeostasis, which eventually leads to hypocalcemia. The principal stimulus of PTH secretion is the extracellular $\mathrm{Ca}^{2+}$ level, which affects $\mathrm{Ca}^{2+}$ sensitive receptors. Activation of these receptors can inhibit the secretion of PTH that is mediated by intracellular signaling pathways [18]. However, the intracellular signaling pathways associated with the pathogenesis of SHPT remain uncertain. In parathyroid cells, extracellular $\mathrm{Ca}^{2+}$ evokes the mobilization of intracellular $\mathrm{Ca}^{2+}$ and $\mathrm{Ca}^{2+}$ influx, which regulate the secretion of PTH. The $\mathrm{Ca}^{2+}$ receptor couples to phospholipase $\mathrm{C}(\mathrm{PLC})$, eliciting rapid increases in $\mathrm{IP}_{3}$ and intracellular $\mathrm{Ca}^{2+}$ [19]. Indeed, PLC mediates breakdown of phosphatidylinositol-4,5-bisphosphate into two second messengers, diacylglycerol and $\mathrm{IP}_{3}$ 
[20]. $\mathrm{IP}_{3}$ can activate SOCE with the depletion of ER $\mathrm{Ca}^{2+}$ stores [21]. ATP acts on $\mathrm{IP}_{3}$ to activate $\mathrm{Ca}^{2+}$ release from the ER. Here, we found that TG- or ATP-induced $\mathrm{Ca}^{2+}$ release was inhibited by BTP2 in parathyroid cells, suggesting that SOCE may also be involved in the secretion of PTH.

Our RNA-Seq experiments showed that Orai3 levels were substantially higher than Orai1 and Orai2 levels in SHPT. Numerous studies have shown that the various homologous proteins, the subtypes of Orai and their mediated SOCE, are closely related to many diseases, such as autoimmune diseases, cardiac hypertrophy and arrhythmia, atherosclerosis, muscle pain, and various cancers [22]. Orai3 has also been shown to mediate SOCE in breast cancer cells and to be an estrogen receptor-regulated channel [23]. In our study, we found that SOCE was inhibited by knockdown of Orai3, resulting in a decrease in PTH secretion. These results indicated that Orai3-mediated $\mathrm{Ca}^{2+}$ signaling may be one underlying mechanism of increased PTH secretion in patients with SHPT. It has been reported that PTH is a powerful stimulator of FGF23 synthesis and release and that SOCE stimulates FGF23 transcription [24]. Therefore, the increase in FGF23 levels may be an adaptive response to Orai3-mediated SOCE and PTH levels.

Another major characteristic of SHPT is parathyroid hyperplasia. Phosphate accumulation, increased FGF23 levels, decreased vitamin D activity, and hypocalcemia are persistent stimulants of parathyroid hyperplasia and increased PTH secretion [25,26]. Calcitriol, a metabolite of vitamin D, inhibits the cell cycle regulator c-MYC, inhibits transforming growth factor $a$, and induces p21 to act as cell cycle inhibitor [27]. In breast cancer cells, Orai3 can also change the cell proliferation process through the c-MYC pathway [23]. The effect of Orai3 on the c-MYC pathway and its potential involvement in the dysfunction of parathyroid hyperplasia warrant further investigation.

\section{Conclusions}

We found that the expression level of Orai3 in parathyroid tissue from patients with SHPT was significantly higher than that in individuals without SHPT. We also found that extracellular $\mathrm{Ca}^{2+}$ entry into human parathyroid cells occurred through SOCE. Knockdown of Orai3 in parathyroid gland cells decreased extracellular $\mathrm{Ca}^{2+}$ entry, and the subsequent reduction in SOCE decreased the release of PTH from the cells. We speculate that the disrupted $\mathrm{Ca}^{2+}$ metabolism in CKD increases the level of Orai3 activation. Thus, increased Orai3 activation and expression and Orai3-mediated SOCE lead to increased PTH release to further aggravate the disrupted $\mathrm{Ca}^{2+}$ homeostasis and to eventually contribute to the pathogenesis of SHPT.

\section{Declarations}

Acknowledgements The authors thank the Center for Scientific Research of Anhui Medical University for help in the experiment.

Author contributions Zhangying Lin conceived and designed the experiments, performed the experiments, analyzed the data, prepared figures, authored or reviewed drafts of the paper, approved the final draft. 
Shuhao Wang and Yanxun Han, Junwei Zhu, Suwen Bai, Yang Fang conceived and designed the experiments and approved the final draft. Hailong Shen, Peikun Li and Bing Shen Collected specimens. Kaile Wu and Yehai Liu contributed reagents/materials/analysis tools, authored or reviewed drafts of the paper, and approved the final draft.

Funding This work was supported by the National Natural Science Foundation of China (grant number 81570403), the Natural Science Foundation of Anhui Province (grant number 1808085MH252).

Data availability Some or all data generated or used during the study are available from the corresponding author by request.

\section{Compliance with ethical standards}

Conflict of interest Authors have no conflict of interest to disclose.

Ethical approval All procedures performed in this study involving patients and animals were in accordance with the ethical standards of the Ethics Committee of Anhui Medical University.

Consent to participate Written informed consent was signed by all patients or legal guardians.

Consent for publication All authors have read the manuscript and authorized the submission for publication.

\section{References}

1. Drawz P, Rahman M (2015) Chronic kidney disease. Ann Intern Med 162 (11):ITC1-16. doi:10.7326/AITC201506020

2. Arévalo-Lorido JC, Carretero-Gómez J, García-Sánchez F, Maciá-Botejara E, Ramiro-Lozano JM, Masero-Carretero A, Robles NR, Bureo-Dacal JC (2016) Secondary hyperparathyroidism prevalence and profile, between diabetic and non-diabetic patients with stage 3 to 4 chronic kidney disease attended in internal medicine wards. MiPTH study. Diabetes \& Metabolic Syndrome: Clinical Research \& Reviews 10 (2):S16-S21. doi:10.1016/j.dsx.2016.01.011

3. Bansal N, Zelnick L, Robinson-Cohen C, Hoofnagle AN, Ix JH, Lima JA, Shoben AB, Peralta CA, Siscovick DS, Kestenbaum B, de Boer IH (2014) Serum parathyroid hormone and 25-hydroxyvitamin D concentrations and risk of incident heart failure: the Multi-Ethnic Study of Atherosclerosis. J Am Heart Assoc 3 (6):e001278. doi:10.1161/JAHA.114.001278

4. Komaba H, Shiizaki K, Fukagawa M (2010) Pharmacotherapy and interventional treatments for secondary hyperparathyroidism: current therapy and future challenges. Expert Opin Biol Ther 10 (12):1729-1742. doi:10.1517/14712598.2010.518614

5. Portillo MR, Rodriguez-Ortiz ME (2017) Secondary Hyperparthyroidism: Pathogenesis, Diagnosis, Preventive and Therapeutic Strategies. Rev Endocr Metab Disord 18 (1):79-95. doi:10.1007/s11154017-9421-4 
6. Lu CL, Yeih DF, Hou YC, Jow GM, Li ZY, Liu WC, Zheng CM, Lin YF, Shyu JF, Chen R, Huang CY, Lu KC (2018) The Emerging Role of Nutritional Vitamin D in Secondary Hyperparathyroidism in CKD. Nutrients 10 (12). doi:10.3390/nu10121890

7. Bai S, Wei Y, Hou W, Yao Y, Zhu J, Hu X, Chen W, Du Y, He W, Shen B, Du J (2020) Orai-IGFBP3 signaling complex regulates high-glucose exposure-induced increased proliferation, permeability, and migration of human coronary artery endothelial cells. BMJ Open Diabetes Res Care 8 (1). doi:10.1136/bmjdrc-2020-001400

8. Li P, Rubaiy HN, Chen GL, Hallett T, Zaibi N, Zeng B, Saurabh R, Xu SZ (2019) Mibefradil, a T-type $\mathrm{Ca}(2+)$ channel blocker also blocks Orai channels by action at the extracellular surface. $\mathrm{Br} \mathrm{J}$ Pharmacol 176 (19):3845-3856. doi:10.1111/bph.14788

9. Zeng B, Chen GL, Garcia-Vaz E, Bhandari S, Daskoulidou N, Berglund LM, Jiang H, Hallett T, Zhou LP, Huang L, Xu ZH, Nair V, Nelson RG, Ju W, Kretzler M, Atkin SL, Gomez MF, Xu SZ (2017) ORAI channels are critical for receptor-mediated endocytosis of albumin. Nat Commun 8 (1):1920. doi:10.1038/s41467-017-02094-y

10. Hou X, Pedi L, Diver MM, Long SB (2012) Crystal structure of the calcium release-activated calcium channel Orai. Science 338 (6112):1308-1313. doi:10.1126/science.1228757

11. Berridge MJ, Bootman MD, Roderick HL (2003) Calcium signalling: dynamics, homeostasis and remodelling. Nat Rev Mol Cell Biol 4 (7):517-529. doi:10.1038/nrm1155

12. Azimi I, Milevskiy MJG, Chalmers SB, Yapa K, Robitaille M, Henry C, Baillie GJ, Thompson EW, Roberts-Thomson SJ, Monteith GR (2019) ORAI1 and ORAI3 in Breast Cancer Molecular Subtypes and the Identification of ORAI3 as a Hypoxia Sensitive Gene and a Regulator of Hypoxia Responses. Cancers (Basel) 11 (2). doi:10.3390/cancers11020208

13. Motiani RK, Abdullaev IF, Trebak M (2010) A novel native store-operated calcium channel encoded by Orai3: selective requirement of Orai3 versus Orai1 in estrogen receptor-positive versus estrogen receptor-negative breast cancer cells. J Biol Chem 285 (25):19173-19183. doi:10.1074/jbc.M110.102582

14. Motiani RK, Zhang X, Harmon KE, Keller RS, Matrougui K, Bennett JA, Trebak M (2013) Orai3 is an estrogen receptor alpha-regulated $\mathrm{Ca}(2)(+)$ channel that promotes tumorigenesis. FASEB J 27 (1):6375. doi:10.1096/fj.12-213801

15. Saliba Y, Keck M, Marchand A, Atassi F, Ouillé A, Cazorla O, Trebak M, Pavoine C, Lacampagne A, Hulot J-S, Farès N, Fauconnier J, Lompré A-M (2015) Emergence of Orai3 activity during cardiac hypertrophy. Cardiovascular Research 105 (3):248-259. doi:10.1093/cvr/cvu207

16. Bogeski I, Kummerow C, Al-Ansary D, Schwarz EC, Koehler R, Kozai D, Takahashi N, Peinelt C, Griesemer D, Bozem M, Mori Y, Hoth M, Niemeyer BA (2010) Differential redox regulation of ORAI ion channels: a mechanism to tune cellular calcium signaling. Sci Signal 3 (115):ra24. doi:10.1126/scisignal.2000672

17. Guo J, Zhao R, Zhou M, Li J, Yao X, Du J, Chen J, Shen B (2020) TRPP2 and STIM1 form a microdomain to regulate store-operated $\mathrm{Ca}(2+)$ entry and blood vessel tone. Cell Commun Signal 18 
(1):138. doi:10.1186/s12964-020-00560-7

18. Bilezikian JP, Cusano NE, Khan AA, Liu JM, Marcocci C, Bandeira F (2016) Primary hyperparathyroidism. Nat Rev Dis Primers 2:16033. doi:10.1038/nrdp.2016.33

19. Brown EM, Gamba G, Riccardi D, Lombardi M, Butters R, Kifor O, Sun A, Hediger MA, Lytton J, Hebert SC (1993) Cloning and characterization of an extracellular $\mathrm{Ca}(2+)$-sensing receptor from bovine parathyroid. Nature 366 (6455):575-580. doi:10.1038/366575a0

20. Nemeth EF, Steffey ME, Hammerland LG, Hung BC, Van Wagenen BC, DelMar EG, Balandrin MF (1998) Calcimimetics with potent and selective activity on the parathyroid calcium receptor. Proc Natl Acad Sci U S A 95 (7):4040-4045. doi:10.1073/pnas.95.7.4040

21. Motiani RK, Stolwijk JA, Newton RL, Zhang X, Trebak M (2013) Emerging roles of Orai3 in pathophysiology. Channels (Austin) 7 (5):392-401. doi:10.4161/chan.24960

22. Lacruz RS, Feske S (2015) Diseases caused by mutations inORAI1 andSTIM1. Annals of the New York Academy of Sciences 1356 (1):45-79. doi:10.1111/nyas.12938

23. Faouzi M, Kischel P, Hague F, Ahidouch A, Benzerdjeb N, Sevestre H, Penner R, Ouadid-Ahidouch H (2013) ORAl3 silencing alters cell proliferation and cell cycle progression via c-myc pathway in breast cancer cells. Biochim Biophys Acta 1833 (3):752-760. doi:10.1016/j.bbamcr.2012.12.009

24. Zhang B, Yan J, Umbach AT, Fakhri H, Fajol A, Schmidt S, Salker MS, Chen H, Alexander D, Spichtig D, Daryadel A, Wagner CA, Foller M, Lang F (2016) NFkappaB-sensitive Orai1 expression in the regulation of FGF23 release. J Mol Med (Berl) 94 (5):557-566. doi:10.1007/s00109-015-1370-3

25. Duque EJ, Elias RM, Moyses RMA (2020) Parathyroid Hormone: A Uremic Toxin. Toxins (Basel) 12 (3). doi:10.3390/toxins12030189

26. Jamal SA, Miller PD (2013) Secondary and tertiary hyperparathyroidism. J Clin Densitom 16 (1):6468. doi:10.1016/j.jocd.2012.11.012

27. Mizobuchi M, Ogata H, Koiwa F (2019) Secondary Hyperparathyroidism: Pathogenesis and Latest Treatment. Ther Apher Dial 23 (4):309-318. doi:10.1111/1744-9987.12772

\section{Figures}


a

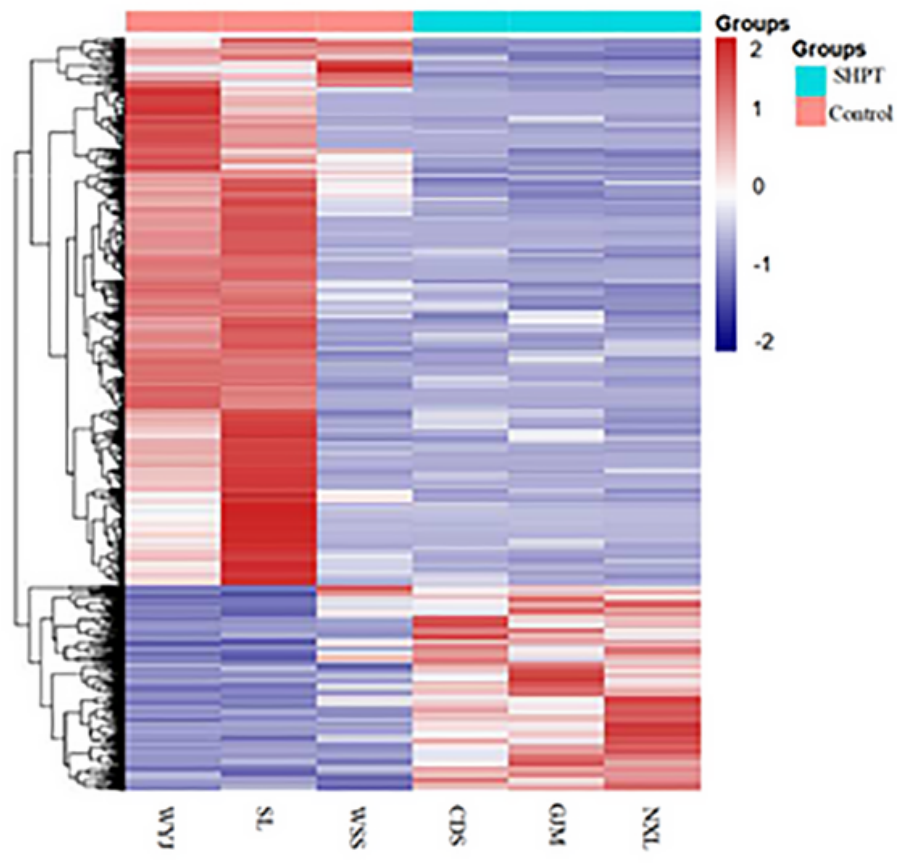

C

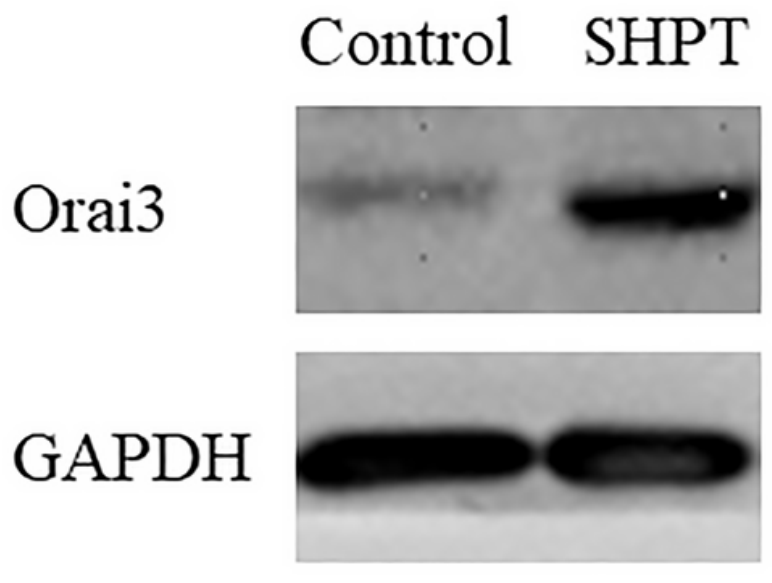

b

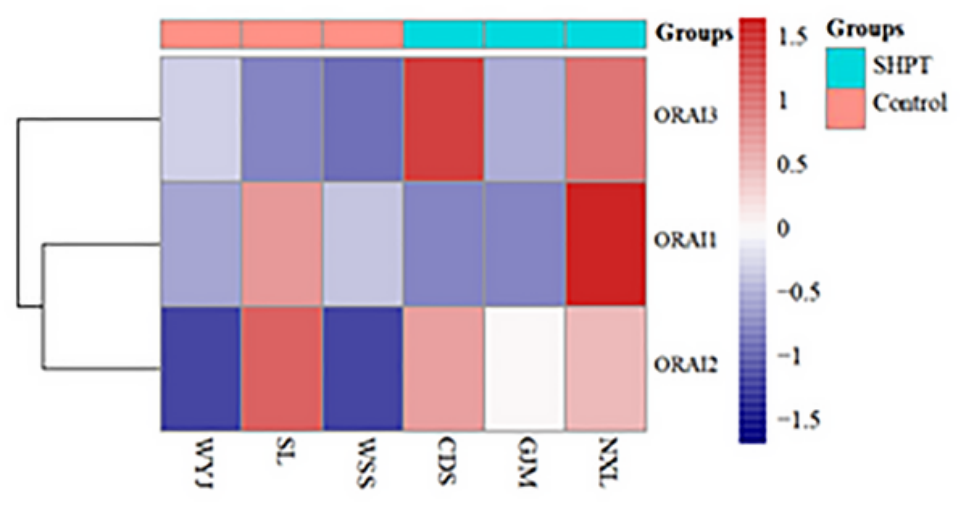

d

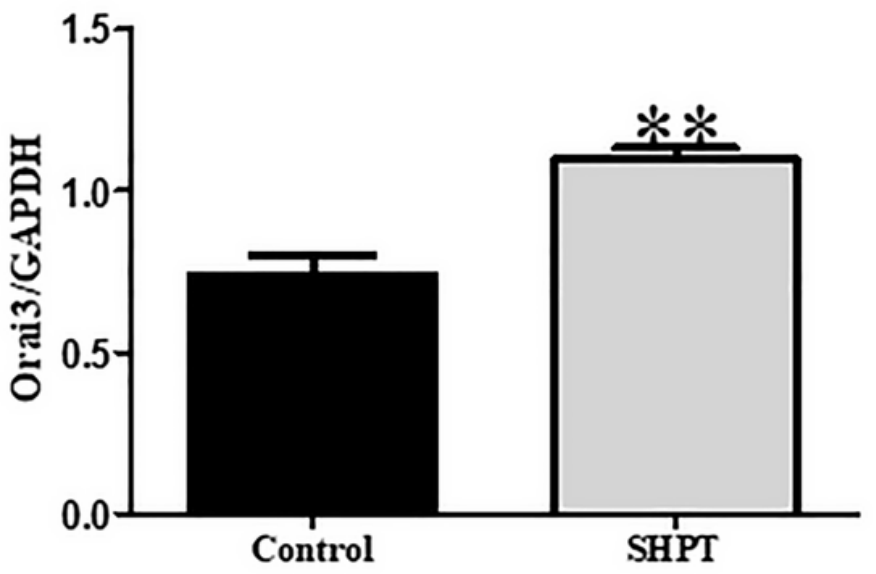

\section{Figure 1}

Orai3 genes are differentially expressed in secondary hyperparathyroidism (SHPT). (a) Clustergram analysis of genes differentially expressed between normal parathyroid tissue from three control patients (WYJ, SL, and WSS) and parathyroid tissue from three patients (CDS, GJM, and NXL) with SHPT. (b) Heatmap showing the differential expression of Orai genes between tissues from three control patients and three patients with SHPT. Representative western blot images (c) and summary data (d) showing Orai3 protein expression in normal parathyroid tissue and in parathyroid tissue from patients with SHPT. 
GAPDH was used as loading control. Protein levels are expressed as relative optical density normalized to $\beta$-tubulin. Mean \pm SEM $(n=3)$. ${ }^{*} P<0.01$ compared with control.
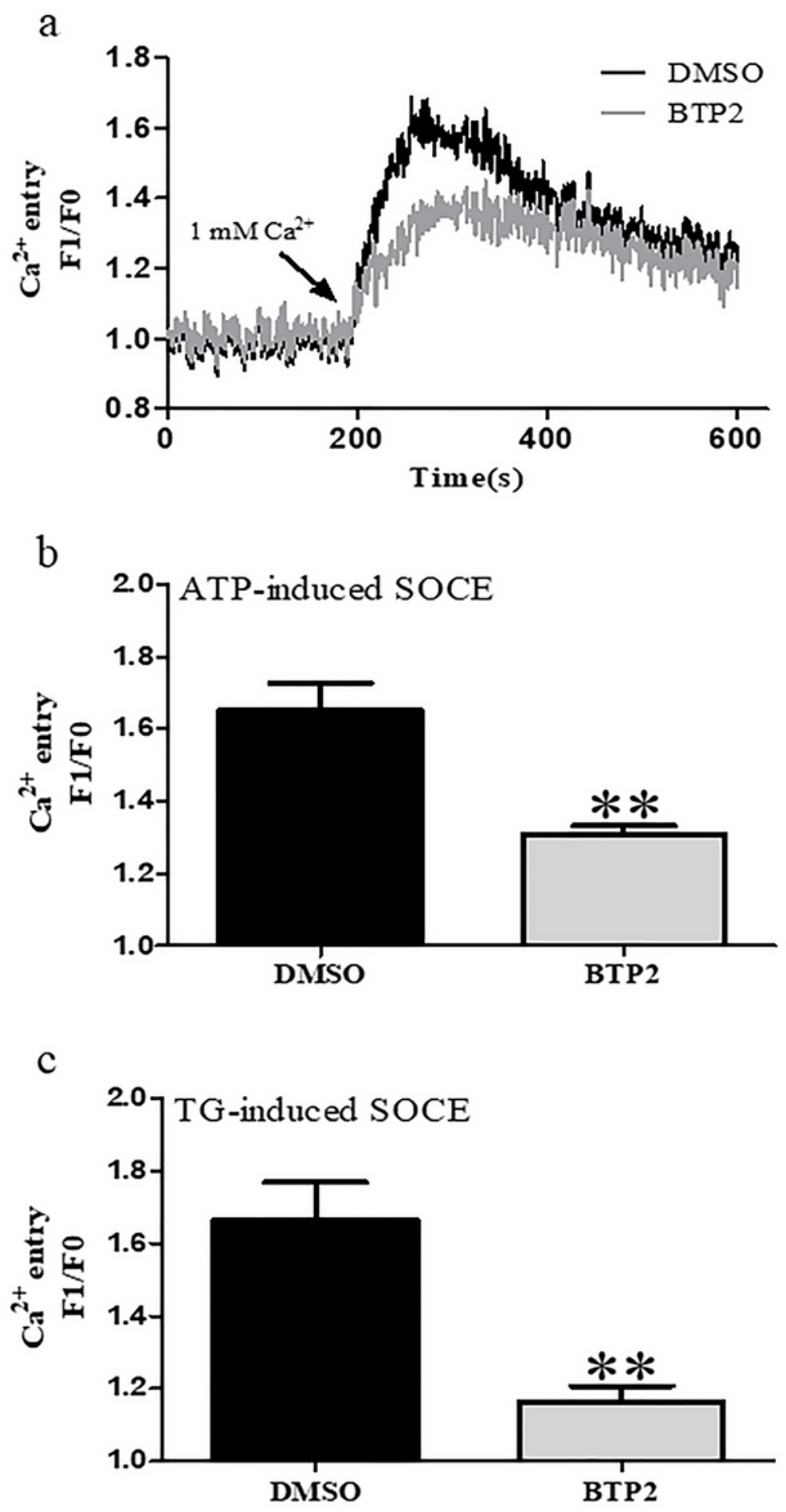

Figure 2

Store-operated calcium (Ca2+) entry (SOCE) is inhibited by BTP2 in parathyroid cells. (a) Representative traces showing that after $\mathrm{Ca} 2+$ release from the endoplasmic reticulum is evoked by adenosine triphosphate (ATP, $100 \mu \mathrm{M})$ or thapsigargin $(\mathrm{TG}, 2 \mu \mathrm{M})$ in a Ca2+-free saline solution, the addition of Ca2+ 
$(1 \mathrm{mM})$ to the solution induces an increase in the intracellular $\mathrm{Ca} 2+$ concentration $([\mathrm{Ca} 2+] \mathrm{i})$ in parathyroid cells treated with DMSO (control) or BTP2 $(10 \mu \mathrm{M})$. (b, c) Summary data showing changes in the [Ca2+]i increase in response to the extracellular $\mathrm{Ca} 2+$ application after ATP (b) or TG (c). Data represent the mean \pm standard error of the mean $(S E M)(n=5-6) . * * P<0.01$ compared with DMSO treatment.

a

\section{Orai3}

$\beta$-Tublin

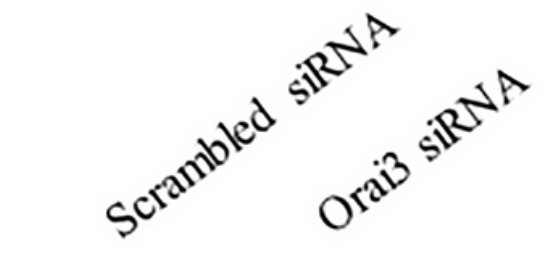

C

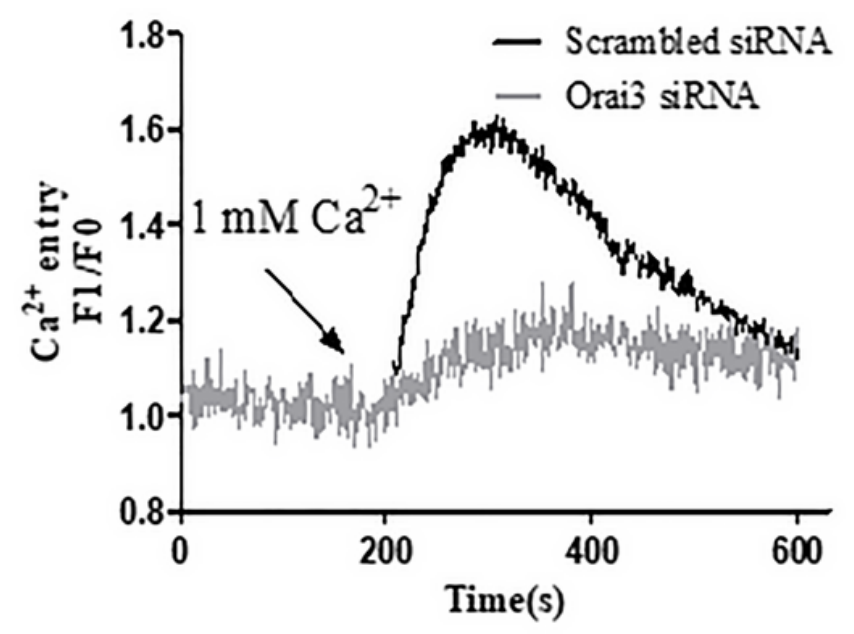

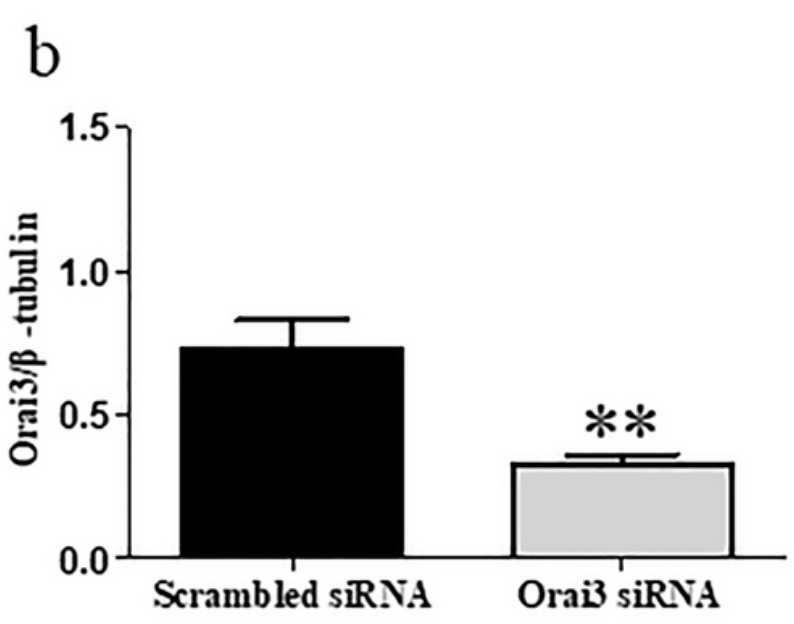

d

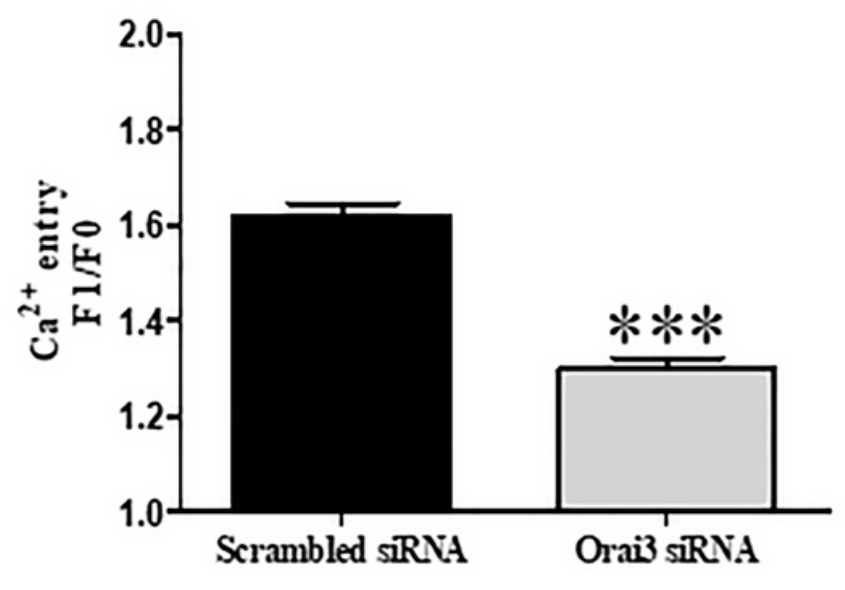

Figure 3

Orai3 mediates store-operated calcium (Ca2+) entry (SOCE) in parathyroid cells. (a) Representative images of western blots and (b) summary data showing the transfection efficiency of Orai3-specific small interfering RNA (siRNA). Data represent the mean \pm SEM $(n=6) ; * P<0.05$ compared with parathyroid cells transfected with scrambled siRNA (control). (c) Representative traces and (d) summary data showing $1 \mathrm{mM} \mathrm{Ca2}+$ application-induced rise in intracellular Ca2+ concentration in parathyroid cells transfected with scrambled siRNA (control) or with Orai3 siRNA following treatment with $500 \mu \mathrm{M}$ ATP for 
10 min in a Ca2+-free saline solution. Data represent the mean \pm SEM $(n=9) .{ }^{\star} * * P<0.001$ compared with parathyroid cells transfected with scrambled siRNA (control).
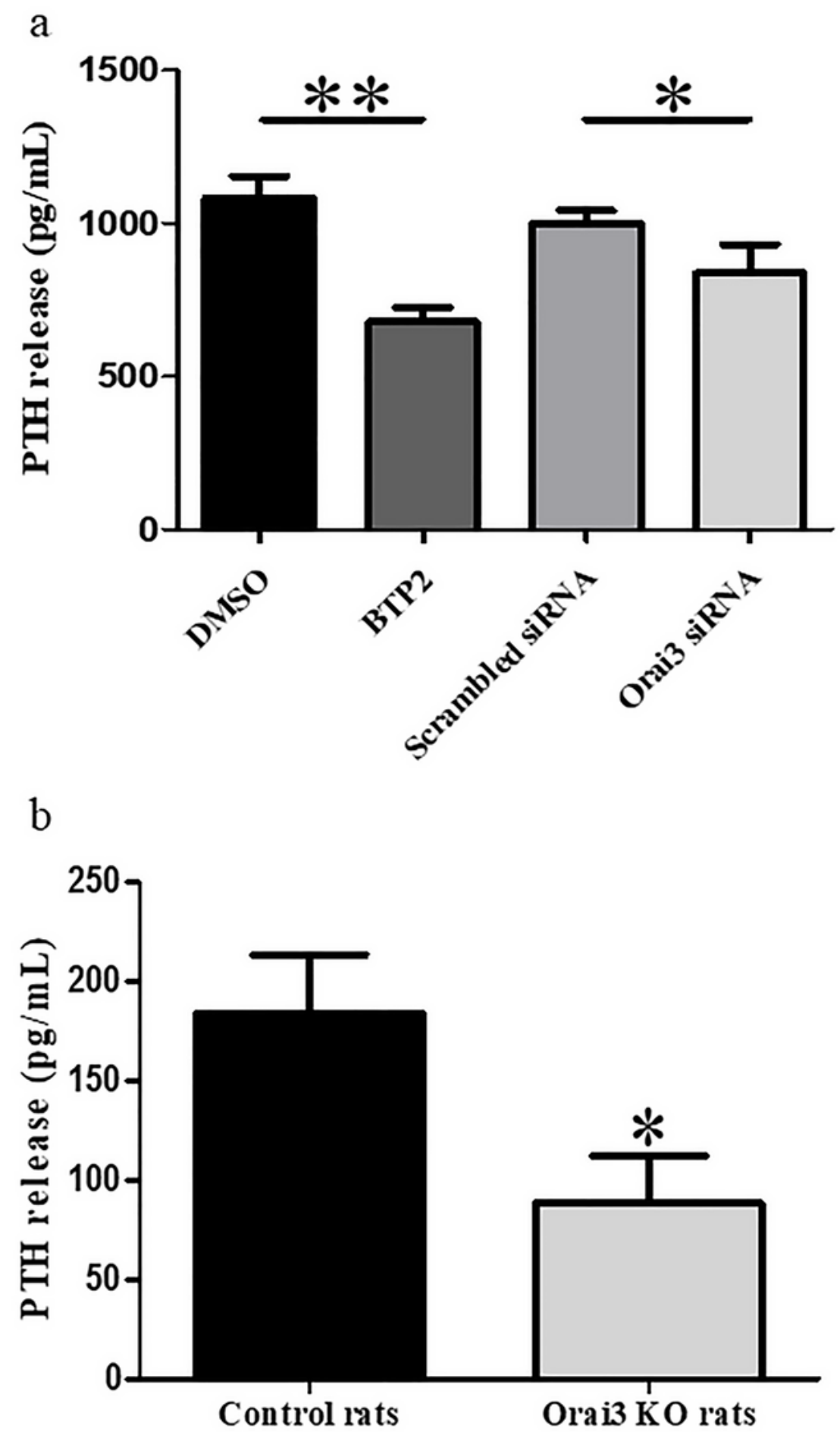

Figure 4

Effect of Orai3 on parathyroid hormone (PTH) release. (a) Compared with parathyroid cells transfected with scrambled small interfering RNA (siRNA), cells transfected with Orai3 siRNA or cells treated with BTP2 $(10 \mu M)$ show a significant decrease in PTH release. Data represent the mean \pm SEM $(n=5)$. 
${ }^{*} \mathrm{P}<0.01$ compared with the DMSO-treated group, ${ }^{*} \mathrm{P}<0.05$ compared with parathyroid cells transfected with scrambled siRNA control. (b) The PTH level in blood obtained from Orai3 knockout (KO) rats is significantly lower than that taken from control rats. Data represent the mean \pm SEM $(n=11)$. ${ }^{*}<0.05$ compared with control rats. 